\title{
SIZE EFFECT AND STOCK BEHAVIOR DURING THE EXPANSION AND CONTRACTION PHASES OF ECONOMIC CYCLE An Empirical Evidence from Indonesian Stock Market
}

\author{
Marwan Asri Sw.
}

Banz (1981) and Reiganum (1981) claim that, in terms of return creation, smallfirms tend to perform better than large firms. They implicitly claim that the phenomena (which is known as size effect) is stable and exists over the period of examination. This study intends to investigate the existence of size effect in Indonesian market and more specifically, to test whether stages of economic cycle (expansion and contraction stages) determine the existence of the effect.

The results of the study show that size effect does exist in the market for the whole period of observation (1991-2001). However, when the period is divided into two parts according to the stage of economic cycle, the statistical analysis results are not supportive to the conclusion about the size effect.

Keywords: capital market; economic cycle; size effect 


\section{Introduction}

Banz (1981) and Reiganum (1981) report the existence of anomaly in stock returns with respect to firm size, which is then widely known as a size effect. They find a significant negative relation between returns and market value of common equity for samples in NYSE and AMEX firms, respectively. More specifically, they contend that smaller firms tend to yield higher returns than the predicted return by using Capital Asset Pricing Model (CAPM). Since then, there are quite number of studies undertaken with regards to the size effect. For the period of 1980's itself for instance, related studies were performed by Roll (1981), Zeghal (1984), Brown et al. (1983), Keim (1983), and some others.

Whereas Banz and Reiganum implicitly assume that the size effect is stable and exists over the period of examination, some other researchers find some different patterns. Brown et al. (1983), for instance, document a reversal of the size anomaly for certain years, and thus reject the hypothesis of stationary year-to-year abnormal return with regard to size. Later, some studies even find evidence that is contrary to the size effect. Bhardwaj and Brooks (1993), for example, conclude that small firm stocks underperform the larger ones. Most of them find that the size effect hypothesis is not valid for all periods.

A number of research have been directed to the relationship between the size effect and economic conditions. Chan et al. (1985), for instance, investigate the size effect for the period of 1958-1977 in US market. They conclude that smaller firm returns fluctuate more with economic expansions and contractions than do large ones. They show further that changes in default risk premium are positively related to the changes in economic conditions. Kim and Burnie (2002) perform another study regarding the size effect and economic cycle. Using alpha, residual and regression methods in their study, they confirm the occurrence of small firm effect in the expansion phase of the economic cycle but not in the contraction phase.

Along with the mentioned studies, this study is intended to test the existence of the size effect in Indonesian market in different phases of economic cycle by applying partly the idea and procedures employed by Kim and Burnie (2002). In the beginning section, the characteristics of small firm proposed by Chan and Chen $(1991)^{1}$ is investigated. Their findings are considered as the basis for the hypothesis. Following Kim and Burnie (2002), this study hypothesizes that the size effect is determined by the economic cycle.

\section{Research Methodology}

A more descriptive analysis is presented before we analyze the existence of size effect during the expansion and contraction periods using some quantitaive techniques. This analysis is intended to investigate more deeply some possible characteristic differences between small and large businesses, especially in terms of their productivity and financial leverage. Referring Chan and Chen's study (1991), Return on Assets (ROA) and DebtEquity Ratio (D/E) are used to approximate company's productivity and financial leverage, respectively. In their study, Chan and Chen contend that smaller firms tend to have lower productivity and higher

\footnotetext{
${ }^{1}$ In their study, Chan and Chen (1991) demonstrate that small firms have lower productivity (measured by return on assets) and higher financial leverage (as measured by debt-equity ratio) than the larger ones.
} 
Asri Sw.-Size Effect and Stock Behavior during the Expansion and...

financial leverage, and therefore higher financial risks.

We apply two methods to test the existence of size effect in Indonesian market. First, we estimate alpha (a) coefficient, which reflects the risk adjusted abnormal return of a particular portfolio (Jensen 1968). Alpha coefficient is calculated by using two models: using singlebeta market model (Equation 1) and dualbeta market model (Equation 2). More precisely, by calculating alpha coefficient using single-beta model, we test whether small-sized portfolios have higher Jensen's risk adjusted abnormal returns than do the larger ones.

$$
\mathrm{R}_{\mathrm{it}}=\alpha_{\mathrm{i} 1}+\beta_{\mathrm{i} 1} \mathrm{R}_{\mathrm{mt}}+\mathrm{e}_{\mathrm{it}}
$$

Where:

$\mathrm{R}_{\mathrm{it}}=$ Return on $i^{\text {th }}$ portfolio at time $t$,

$\mathrm{R}_{\mathrm{mt}}=$ Return on market portfolio at time $t$.

Dual-beta model is employed in order to differentiate the magnitude of size effect between expansion and contraction periods. This model is used under the assumption that risks, and hence the returns of securities, change in accordance with economic cycle. As mentioned by Kim and Burnie, this model is described in Bhardwaj and Brooks (1993). In this model, the phase of economic cycle is introduced as a dummy variable, with a value of 0 (zero) if the economy is in a contraction phase and 1 (one) otherwise. In order to accommodate the changes in security risk as well as in risk premiums for the expansion period, additional intercept $\left(\delta_{i \alpha}\right)$ and slope $\left(\delta_{i \beta}\right)$ are introduced in the model.

$$
\mathrm{R}_{\mathrm{it}}=\alpha_{\mathrm{i} 2}+\delta_{\mathrm{i}} \mathrm{Z}_{\mathrm{t}}+\beta_{\mathrm{i} 2} \mathrm{R}_{\mathrm{mt}}+\delta_{\mathrm{i} \beta} \mathrm{Z}_{\mathrm{t}} \mathrm{R}_{\mathrm{mt}}+\mathrm{e}_{\mathrm{it}}
$$

Where:

$\mathrm{R}_{\mathrm{it}}=$ Return on $i^{\text {th }}$ portfolio at time $t$,
$\mathrm{R}_{\mathrm{m}}=$ Return on market portfolio at time $t$, $\alpha_{\mathrm{i} 2}=$ intercept for contraction period,

$\alpha_{i 2}+\delta_{i \alpha}=$ intercept for expansion period, $\beta_{\mathrm{i} 2}=$ slope for contraction period,

$\beta_{\mathrm{i} 2}+\delta_{\mathrm{i} \beta}=$ slope for expansion period.

The second approach used in this study is basically an application of a regression model that accommodates the impact of economic cycle on small firm returns. Different from Kim and Bernie, changes in money supply (M2) are used as the indicator of economic contraction or economic expansion. The economy is considered in expansion phase if there is a positive change of $M 2$, or otherwise if the change is negative. The model is shown in Equation 3.

$$
\mathrm{R}_{\mathrm{it}}=\alpha_{\mathrm{i} 3}+\beta_{\mathrm{i} 2} \mathrm{R}_{\mathrm{mt}}+\gamma_{\mathrm{i} 3} \Delta \mathrm{M}_{\mathrm{t}}+\mathrm{e}_{\mathrm{it}}
$$

Where

$\mathrm{R}_{\mathrm{mt}}=$ Return on market portfolio at time $t$ (used as a control variable),

$\Delta \mathrm{M}_{\mathrm{t}}=$ change in money supply (M2) at time $t$.

In the presence of size effect, the $\gamma_{i}$ coefficient will be positive and significant for small-sized portfolio and negative-significant for larger portfolio. Otherwise, the economic cycle do not influence the presence of size effect.

\section{Data and Sample Selection}

The study includes 237 stocks issued in the Jakarta Stock Exchange (JSX). The monthly returns are calculated for elevenyear period (January 1991 to December 2001). Those samples are then arranged into ten groups of portfolios according to their sizes (as measured by market capitalization) and ranked in ascending order. The data of money supply (M2) is collected from the reports of Bank Indonesia. Table 1 shows the characteristic of those 
ten portfolios during the period of observation. Portfolios' productivity is reflected by the return on assets (average ROA) while the portfolios' leverage can be studied from the average debt-equity (D/E) ratios. Table 2 consists of average return and standard deviation of return for each portfolio.

\section{Analysis}

\section{Descriptive Analysis}

Before conducting the alpha and regression procedures, we perform a descriptive analysis in order to find out whether Chan and Chen's (1991) findings are valid for the Indonesian stock market. In their study, Chan and Chen conclude that small firms have less productivity and more leverage than those larger ones. Table 1 consists of average return on assets (ROA) and debt to equity ratios (D/E) of ten size-based portfolios. The table shows that in general, the average return of assets have relatively consistent upward trend as the firm size increases during the period of observation (1991-2001). In other words, figures in Table 1 support Chen and Chan's findings regarding the productivity of small firms. Figure 1 gives us a clearer indication about the "direction" of firm size and return on assets. The "ROA line" shows an upward trend following the increase of firm size.

On the other hand, Table 1 shows a relatively different fact regarding the comovement between companies' sizes and their average debt-to-equity ratio. The last

Table 1. Return on Assets and Debt to Equity Ratio of Ten Portfolios

\begin{tabular}{|c|c|c|}
\hline Portfolio & ROA & D/E \\
\hline 1 & 1.306 & 3.763 \\
\hline 2 & 1.273 & 3.119 \\
\hline 3 & 0.994 & 1.911 \\
\hline 4 & 1.197 & 5.826 \\
\hline 5 & 1.919 & 2.776 \\
\hline 6 & 1.733 & 6.462 \\
\hline 7 & 2.929 & 7.411 \\
\hline 8 & 3.592 & 3.009 \\
\hline 9 & 2.758 & 2.357 \\
\hline 10 & 4.931 & 2.656 \\
\hline
\end{tabular}

Figure 1. Return on Assets and Debt to Equity Ratio of Ten Portfolios

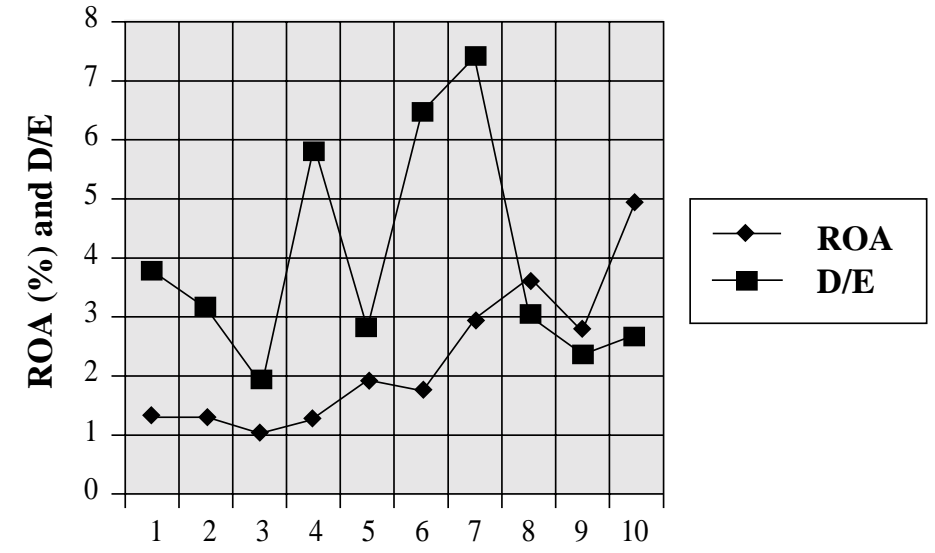

Portfolio 
Asri Sw.-Size Effect and Stock Behavior during the Expansion and...

row of the table shows no consistent increase or decrease trend of debt-to-equity ratios across the firm sizes for all periods. Figure 1 supports our findings about the relationship between financial leverage and firm size. The figure shows visually that the average $\mathrm{D} / \mathrm{E}$ ratios do not move consistently to a particular direction as the firm size increases. Therefore, in terms of leverage, we cannot confirm Chan and Chen's findings.

The average returns and standard deviation of each portfolio are also calculated and the results are summarized in Table 2. We present the portfolio returns in several ways. First we show the average return for the whole period throughout the year (January-December). Second, in order to isolate January's anomaly, we separate January from the other months of the year and we calculate the average returns for February-December for the whole year of observation. Finally, we separate the average portfolio returns for two different stages of the economic cycle, namely expansion period and contraction periods.

For the full-year period (JanuaryDecember), which includes 132 monthly return data, portfolio 1 has an average returns of 8.133 percent, which is more than six times greater than that of portfolio $10(1.237 \%)$. Also in general, we find a consistent decreasing pattern of average return as the firm size increases. We find a similar pattern when we focus our attention to February-December, which involves 121 monthly return data. The average return of portfolio $1(8.634 \%)$ is more than eight times higher than the average return of portfolio 10 (which is only $0.989 \%$ ). Again, if we look at the entire portfolios, we find another decreasing trend

Table 2. Average Returns and Returns' Standard Deviation of Ten Portfolios (1991-2001)

\begin{tabular}{|c|c|c|c|c|c|c|c|c|c|c|}
\hline \multirow[t]{2}{*}{ Portfolio } & \multicolumn{2}{|c|}{$\begin{array}{l}\text { January- } \\
\text { December }\end{array}$} & \multicolumn{2}{|c|}{ Januari } & \multicolumn{2}{|c|}{$\begin{array}{l}\text { February- } \\
\text { December }\end{array}$} & \multicolumn{2}{|c|}{ Expansion } & \multicolumn{2}{|c|}{ Contraction } \\
\hline & AvRet & SD & vet & SD & vRet & SD & AvRet & SD & AvRet & SD \\
\hline 1 & 8.1 & 0.079 & 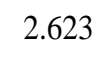 & 59 & 4 & 0.08 & ק & 0.072 & 8 & 0.124 \\
\hline 2 & 8.098 & 0.067 & -0.458 & 0.056 & 8.876 & 0.068 & 216 & 0.066 & 13.039 & 0.071 \\
\hline 3 & 5.681 & 0.059 & -3.816 & 0.056 & 6.544 & 0.059 & 5.717 & 0.059 & 5.479 & 0.051 \\
\hline 4 & 5.349 & 0.049 & -0.499 & 0.062 & 5.882 & 0.048 & 5.321 & 0.049 & 5.512 & 0.049 \\
\hline 5 & 5.434 & 0.053 & -0.735 & 0.048 & 5.994 & 0.054 & 5.757 & 0.054 & 3.622 & 0.047 \\
\hline 6 & 2.874 & 0.045 & -3.026 & 0.045 & 3.417 & 0.045 & 2.091 & 0.045 & 7.263 & 0.042 \\
\hline 7 & 2.09 & 0.048 & 579 & 0.045 & 1.591 & 0.048 & 2.049 & 0.043 & 2.316 & 0.079 \\
\hline 8 & 0.519 & 0.037 & -1.327 & 0.039 & 0.688 & 0.037 & 0.076 & 0.037 & 3.006 & 0.04 \\
\hline 9 & 1.316 & 0.036 & 0.603 & 0.039 & 1.381 & 0.036 & 1.542 & 0.036 & 0.049 & 0.038 \\
\hline 10 & 1.237 & 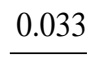 & 3.961 & 0.041 & 0.989 & 0.032 & 0.147 & $\underline{0.032}$ & 7.34 & 0.036 \\
\hline verage & 4.073 & 0.051 & 0.491 & 0.05 & 4.399 & 0.051 & 3.896 & 0.049 & 5.052 & 0.058 \\
\hline
\end{tabular}


following the increase of company size. ${ }^{2}$ These results are consistent with Banz (1981), Reiganum (1981) and other researchers' findings that smaller firms have greater returns than do larger firms. Figure 2a provides a clear visual explanation about this matter. The January-December and February-December average returns are represented by two negative-sloped lines, indicating negative relation between average returns and firm size.

Table 2 also indicates that smaller firms have higher degree of risk (as measured by the standard deviation of returns). For the whole year period (January-December), portfolio 1 has a standard deviation of 0.079 , which is more than twice as much as portfolio 10's (which is 0.033). This is also valid for "January only" and February-December period. For "January only", the standard deviation of the first portfolio is about 1.7 times greater than that of the tenth portfolio, while for February-December the standard deviation of portfolio 1 is 2.5 times bigger than the standard deviation of portfolio 10 .

As mentioned previously, this study employs change in money supply (M2) as an indicator of economic cycle. If $M 2$ has a positive change, then we define the economy as in the expansion stage. Conversely, we define the economy as in contraction stage if there is a negative change in M2. For the eleven-year period (19912001), using monthly data, we identify 114 months of expansion and 18 months of contraction.

Table 2 also shows the average returns (and risks) of each portfolio as presented in the last four columns. During the expansion period, the average returns of smaller firms are significantly higher than that of larger firms. The average return of portfolio 1 is 9.069 percent, which is ex-

Figure 2a. Average Returns of Ten Portfolios for January-December, January only, and February-December

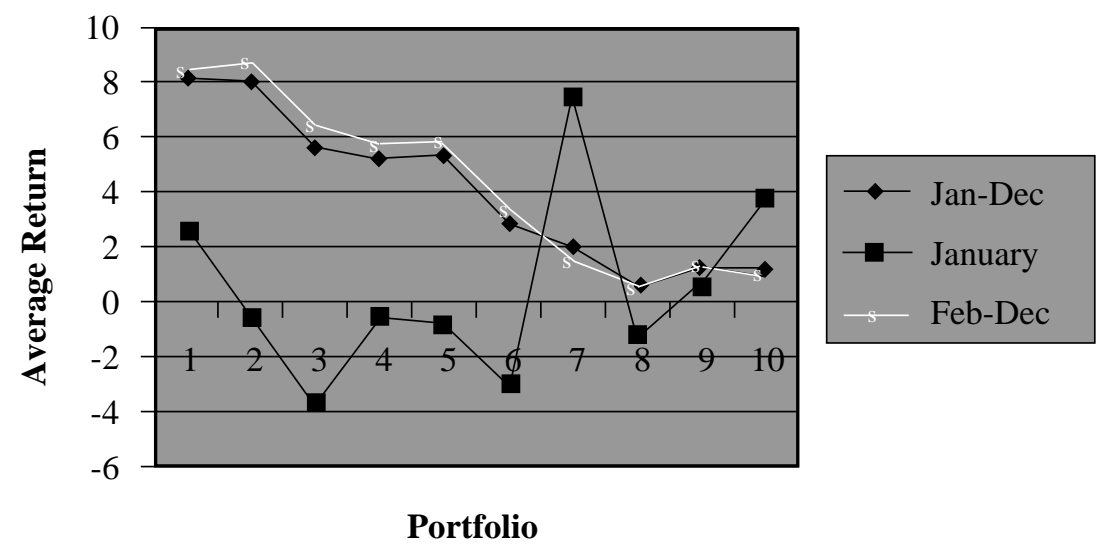

\footnotetext{
${ }^{2}$ However, this trend is not valid for January's average return. As we can see from Table 2 and Figure 2a, the average returns of ten portfolios for "January only" tend to be randomly distributed. They do not form any specific trend, either positively or negatively sloped.
} 
Asri Sw.-Size Effect and Stock Behavior during the Expansion and...

Figure 2b. Average Returns of Ten Portfolios for Expansion and Contraction Periods

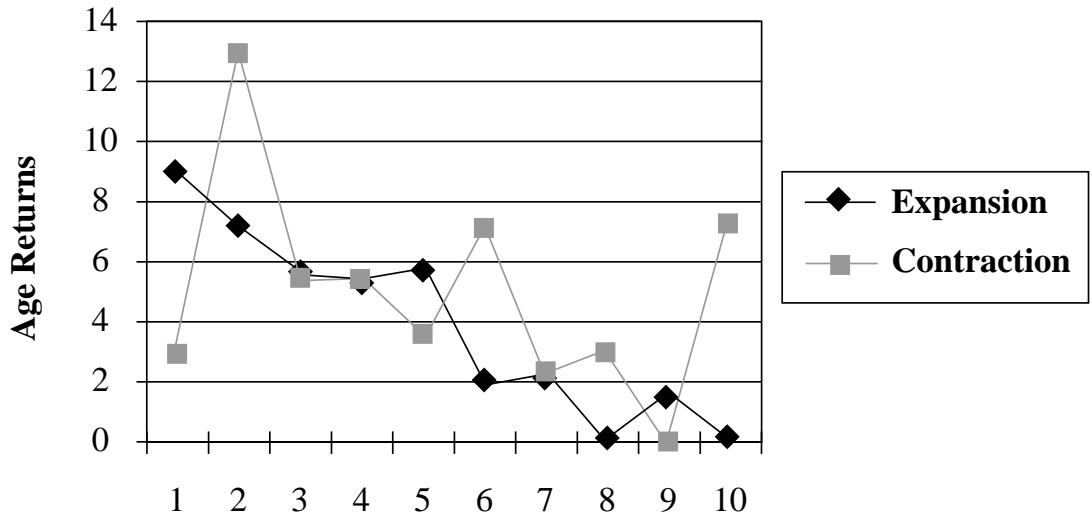

Portfolio

tremely higher than that of portfolio 10 $(0.147 \%)$. If we investigate all portfolios, then we find that average returns consistently decrease as the size of firm increases. In other words, we confirm the existence of size effect in the expansion period. This finding is similar to Kim and Burnie's for American data.

However, during the contraction period, average returns do not form any particular trend. As shown in the table, the average returns during the contraction period tend to be randomly distributed across portfolios. These results indicate that size effect is not confirmed for the contraction period of Indonesian economy. This finding is different from Kim and Burnie's, where size effect is also present during the contraction period of US economy.

Figure 2a shows visually the trends of average returns for both stages following the increase of firm size. The "expansion" line has a negative slope, which indicates that the average returns decreases as the firm size increases. The "contraction" line does not show clearly positive or negative trend.

\section{Alpha and Regression Analysis}

The results of alpha calculation using Equation 1 (for single beta) and Equation 2 (for dual beta) are presented in Table 3 . The table is divided into three panels. The first panel shows alpha coefficients when we include all months (January-December) in calculation. The second panel refers to "January only", while the last panel shows the results of February-December alpha calculation.

Table 3, Panel A shows that using single beta model, we find that smaller size firms have higher $\alpha$ estimate than do larger ones. $\alpha$ estimate of Portfolio 1 $(0.085)$ for instance, is much higher and more significant than that of portfolio 10 in Panel A. This finding is valid for all panels. Using Jensen's (1968) interpretation, we might conclude that smaller firms have larger abnormal returns than do the larger firms.

The last two columns of Table 3 show alpha estimates for expansion and contraction phases of economic cycle using dual-beta model. If we include all months (January-December) in the calculation, 
Gadjah Mada International Journal of Business, September 2002, Vol. 4, No. 3

Table 3. Alpha Estimate Using Single and Dual Beta Models

\begin{tabular}{|c|c|c|c|}
\hline \multirow{2}{*}{ Portfolio } & \multirow{2}{*}{ SingleBeta } & \multicolumn{2}{|c|}{ Dual Beta } \\
\hline & & Expansion & Contraction \\
\hline \multicolumn{4}{|c|}{ Panel A (Jan-Dec) } \\
\hline 1 & $0.085 * * *$ & 0.098 & 0.030 \\
\hline 2 & $0.075 * *$ & 0.067 & 0.133 \\
\hline 3 & $0.054 * *$ & 0.054 & 0.056 \\
\hline 4 & $0.051 * *$ & 0.052 & 0.057 \\
\hline 5 & 0.043 & 0.042 & 0.038 \\
\hline 6 & $0.023^{*}$ & $0.015^{* *}$ & $0.076^{*}$ \\
\hline 7 & 0.014 & 0.012 & 0.025 \\
\hline 8 & 0.001 & $-0.005^{*}$ & $0.031^{*}$ \\
\hline 9 & 0.008 & 0.009 & 0.002 \\
\hline 10 & 0.007 & $-0.005 * *$ & $0.075^{* *}$ \\
\hline \multicolumn{4}{|c|}{ Panel B (Jan only) } \\
\hline 1 & 0.006 & -0.011 & 0.048 \\
\hline 2 & -0.029 & 0.031 & -0.024 \\
\hline 3 & $-0.056 * *$ & $-0.043 * *$ & $-0.074 *$ \\
\hline 4 & -0.032 & -0.030 & -0.034 \\
\hline 5 & -0.032 & -0.036 & -0.021 \\
\hline 6 & -0.355 & -0.016 & -0.068 \\
\hline 7 & 0.070 & 0.109 & 0.004 \\
\hline 8 & -0.035 & -0.036 & -0.024 \\
\hline 9 & -0.032 & -0.030 & -0.034 \\
\hline 10 & -0.005 & -0.017 & 0.028 \\
\hline \multicolumn{4}{|c|}{ Panel C (Feb-Dec) } \\
\hline 1 & $0.089 * *$ & 0.102 & 0.026 \\
\hline 2 & $0.086 * *$ & $0.074 *$ & 0.167 \\
\hline 3 & $0.064 * *$ & 0.062 & 0.078 \\
\hline 4 & $0.057 * *$ & 0.056 & 0.076 \\
\hline 5 & 0.054 & 0.052 & 0.050 \\
\hline 6 & $0.031 * *$ & $0.020^{* *}$ & $0.107 *$ \\
\hline 7 & 0.012 & 0.010 & 0.028 \\
\hline 8 & 0.004 & $-0.001 * *$ & $0.039 * *$ \\
\hline 9 & 0.011 & 0.012 & 0.008 \\
\hline 10 & 0.007 & $-0.004 * *$ & $0.081 * *$ \\
\hline
\end{tabular}

*** significant at $1 \% ; * *$ significant at $5 \% ; *$ significant at $10 \%$ 
Asri Sw.-Size Effect and Stock Behavior during the Expansion and...

then the values of alpha estimate during expansion period seem to follow the pattern of our previous finding. Portfolio 1 has 0.098 alpha estimate, while Portfolio 10 has only -0.005 , and the alphas tend to have decreasing trend as the firm size increases. However, some alphas are not significant, so we cannot draw any conclusion regarding the size effect. This problem is also found in Panel $\mathrm{C}$, where we exclude "January" from our data set. In this panel we can see that Portfolio 1 has 0.102 alpha estimate, while Portfolio 10 has only -0.004. Again, some alphas are not significant, so we might not be able to draw any conclusion of whether (during the expansion period) smaller companies to provide higher or lower abnormal returns than do the larger firms.

For the contraction period, it is also quite difficult to see the trend of the estimate for this period (for all panels). Alpha estimates fluctuate with the increase of firm size. The alpha estimate for Portfolio 1 (Panel A), for instance, is 0.030 and insignificant while Portfolio 10 has a significant alpha of 0.075 . When firm size increases from Portfolio 4 to Portfolio 5, alpha increases from 0.038 to 0.076 . However, when firm size continues to increase from Portfolio 5 to Portfolio 6, alpha estimate decreases from 0.076 to 0.025 . This inconsistency is found repeatedly in Panel $\mathrm{B}$ and $\mathrm{C}$, and hence, we cannot draw conclusion regarding the pattern of alpha during contraction period. In other words, during the contraction period, the size effect is also inconclusive.

Table 4 shows only the regression coefficient of money supply change variable $(\gamma)$ of each portfolio for three different panels. If the size effect is there, $\gamma$ coefficient will be positive and significant for small-sized portfolio and negative-significant for larger portfolio. These values and signs indicate that small firms have larger average returns than do the big firms, and conversely, small firms perform worse during the contraction period. On the other hand, the presence of size effect is not

\section{Table 4. Regression Coefficient $(\boldsymbol{\gamma})$ of $\boldsymbol{\Delta} \mathbf{M}$ Variable}

\begin{tabular}{|c|c|c|c|}
\hline Portfolio & Panel A (Jan-Dec) & Panel B (Jan only) & Panel C (Feb-Dec) \\
\hline 1 & 0.168 & 0.853 & -0.562 \\
\hline 2 & 0.130 & $0.445 *$ & $0.808 * *$ \\
\hline 3 & 0.055 & $0.671 * *$ & $0.475 *$ \\
\hline 4 & -0.026 & $0.846 * *$ & 0.344 \\
\hline 5 & -0.058 & 0.879 & $1.658 * * *$ \\
\hline 6 & -0.069 & $0.517 * *$ & $0.820 * *$ \\
\hline 7 & -0.090 & 0.619 & $0.917 * * *$ \\
\hline 8 & -0.031 & $0.768 * *$ & $0.630 * * *$ \\
\hline 9 & -0.026 & $0.986 * *$ & $0.672 * * *$ \\
\hline 10 & $-0.075 *$ & $1.092 * *$ & $0.641 * * *$ \\
\hline
\end{tabular}

$* * *$ significant at $1 \%$

** significant at 5\%

* significant at $10 \%$ 
influenced by the stage of economic cycle if values and signs of $\gamma$ do not follow the mentioned pattern.

In Panel A, $\gamma$ for all portfolios are insignificant, even though the trend of $\gamma$ seems to show the presence of size effect. In Panel B and C, we find that even though some of $\gamma$ are significant, their values tend to fluctuate across portfolios. Again, this is an indication that stages of economic cycle do not determine the presence of size effect.

\section{Conclusion}

In general, the empirical results of the study confirm Chan and Chen's finding in terms of relationship between firm size and productivity. Using Indonesian data, we find that smaller firms tend to have larger productivity than do the larger ones. However, the study does not confirm their statement about the size-leverage relationship.

The study confirms the presence of size effect for the whole period of observation. Figures in Table 2 (average returns) and Table 4 (single alpha) show that returns of smaller firm are consistently higher than that of larger firms. However, when we divide the observation period into two parts according to the stages of economic cycle, we cannot confirm the consistency of size effect. Hence, we might draw a final conclusion that the presence of size effect is not determined by the stage of economic cycle.

\section{Reference}

Banz, R. 1981. The Relationship between return and market value of common stock. Journal of Financial Economics.

Bhardwaj, R., and L. Brooks. 1993. Dual betas from bull and bear markets: Reversal of the size effect. Journal of Financial Research.

Brown, P., A. W. Kleidon, T. A. Marsh. 1983. New evidence on the nature of size-related anomalies in stock prices. Journal of Financial Economics 12 (1). Amsterdam.

Chan, K., and N. Chen. 1991. An Unconditional asset-pricing test and the role of firm size as an instrumental variable for risk. Journal of Finance.

Chan, K. C., N. Chen, D. A. Hsieh. 1985. An exploratory investigation of the firm size effect. Journal of Financial Economics 14 (3) Amsterdam.

Jensen, M. C. 1968. The performance of mutual funds in the period 1954-1964. Journal of Finance 23: 389-416.

Keim, D. B. 1983. Size-related anomalies and stock return seasonality: Further empirical evidence. Journal of Financial Economics 12 (1). Amsterdam.

Kim, M. K., and D. A. Burnie. 2002. The firm size efect and economic cycle. The Journal of Financial Research (Spring). Columbia. 
Asri Sw.-Size Effect and Stock Behavior during the Expansion and...

Reiganum, R. 1981. Misspecification of capital asset pricing: Empirical anomalies based on earnings yields and market values. Journal of Financial Economics.

R. Roll. 1981. A possible explanation of the small firm effect. The Journal of Finance 36 (4). Cambridge.

Zeghal, D. 1984. Firm size and the informational content of financial statements. Journal of Financial and Quantitative Analysis 19 (3). Seattle. 